\title{
Fury at plan to split historic biology archive
}

Rex Dalton, San Diego

The auction of an historic archive of molecular-biology documents, planned for the fiftieth anniversary of the publication of the DNA double helix, is drawing fire from scientists.

Top researchers who sold papers to a private California archive on the understanding that they would be kept together in a single, accessible collection are angry that Christie's plans to sell the papers as separate lots. And a collector who gathered the works together is threatening legal action to block the sale.

Christie's is scheduling the sale of 56 lots from the Jeremy Norman Molecular Biology Archive for 25 April in New York, 50 years to the day after Nature published Crick and Watson's paper describing the double helix.

It values the documents at between $\$ 2.2$ million and $\$ 3.3$ million. The lots include documents from Aaron Klug, Max Perutz, Rosalind Franklin, Francis Crick and James Watson. One lot is a signed galley proof of Crick and Watson's Nature paper.

"It is an outrage," says Klug, who won the Nobel Prize in chemistry in 1982 for developing crystallographic electron microscopy. "We were given promises, assurances, that the whole collection would be kept together."

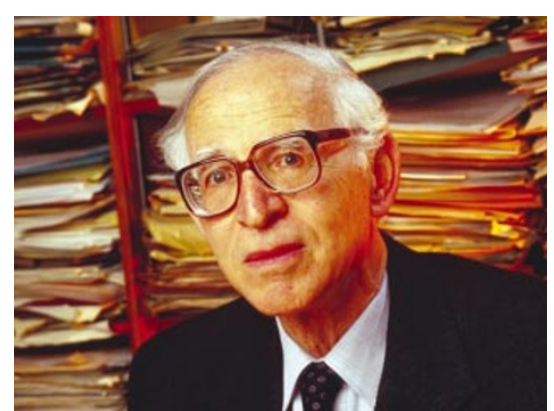

Aaron Klug: private archive sale is 'an outrage'.

Norman declined to be interviewed, saying only that the sale "will be handled appropriately". Christie's officials say that Norman has title to the documents, and that a bid for the entire collection would be willingly entertained.

But Al Seckel, a neuroscientist at the California Institute of Technology (Caltech) in Pasadena and an amateur collector who purchased the documents for Norman, was furious when he learned of the auction. “This impacts on my reputation," he says.

Beginning in the late 1990s, Seckel travelled to Europe to buy molecular-biology papers, which he sold to Norman, a book dealer in San Francisco. Both men said they wanted to create an archive that transcends national borders, putting the history of DNA under one roof, probably at Caltech. For each purchase of papers and sale to Norman, Seckel says there are specific agreements that the documents will be kept together for scholarly work.

But Francis Wahlgren, head of Christie's books and manuscripts department, says that he is "not aware of any agreement". Norman no longer wanted to be responsible for the archive, he adds. In June 2001, Nature reported concern among archivists that the documents might someday be sold at auction, which at the time Norman denied would happen (see Nature 411, 732; 2001).

Norman's archive plans seem to have changed after his failed 2001 effort to acquire Crick's entire document collection. When the sale collapsed, the Wellcome Library in London stepped in to buy them for US $\$ 2.8$ million in November 2001 .

Last week, Seckel tried unsuccessfully to persuade Christie's to stop the sale. He says he will go to court if necessary to block it.

David Pearson, the Wellcome's librarian, says: "Our concern is that very important papers may be disbursed in the private market." The Wellcome is considering its options, he adds.

\section{Harvard team suggests route to better bioterror alerts}

Jonathan Knight, San Francisco

A simple improvement in the way health data are monitored for signs of a bioterror attack could speed up the process and cut the number of false alarms, says a team of specialists at Harvard Medical School.

The findings, reported online this week (B. Y. Reis, M. Pagano and K. D. Mandl Proc. Natl Acad. Sci USA doi:0.1073/ pnas.0335026100; 2003), are expected to influence the current US drive to improve early-warning systems for such attacks.

Public-health officials fear that biological attacks may not be recognized until it is too late to prevent casualties. Smallpox and anthrax, for example, start with 'flu-like symptoms, and the first victims are likely just to be sent home to rest.

Biodefence researchers have been looking at everything from patterns of hospital visits to sales of cough syrup. Dozens of systems are now being field-tested by state and local health departments across the United States. In theory, a sudden outbreak of disease, whether natural or deliberate, will register as a spike in the data, alerting health officials.

But the chief difficulty is separating this from day-to-day variation. "There are a lot of bumps and noise in public healthcare data," says Ben Reis, a biosurveillance specialist with Harvard Medical School at the Children's Hospital in Boston. To prevent false alarms, most systems set the alert threshold so high that they risk missing the first signs of a real outbreak.

The standard approach is to forecast the number of emergency cases that hospitals have to deal with one day at a time, based on historical data. Departures from the forecast send an alert to a regional epidemiologist for further investigation.

Reis designed his system to look at the data a week at a time. He reasoned that the wider window would make it easier to disregard blips that might otherwise register as false positives. It should also spot rising trends earlier than the standard software.

He tested the approach with emergency records from the Children's Hospital, which comprise the main complaint of every patient who checked in from 1992 to 2002 a total of more than 500,000 visits. Because there were no real outbreaks, Reis added simulated ones calculated to look like small or large releases of anthrax or smallpox.

The week-long average was able to reveal outbreaks that the one-day system missed, Reis and colleagues report, because its detection threshold could be set much lower without triggering false alarms.

Marc Overhage, an expert in healthcare informatics at the Regenstrief Institute in Indianapolis, says that false alarms need to be eliminated. Investigations into possible outbreaks are expensive, costing an average of $\$ 50,000$, he says. Too many could render a system worthless. "We shouldn't build all these surveillance networks until we know they work," he says. "Reis is the only one running through how to do it best."

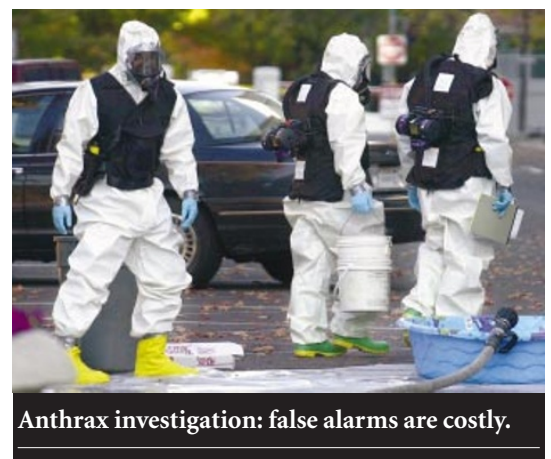

